\title{
Painting Therapy in Improvement of the Symptoms of Children with Autism Spectrum Disorder
}

\author{
Kaveh Moghaddam ${ }^{1, *}$, Aida Ravarian ${ }^{2}$, Farhoud Saied Ershadi ${ }^{3}$ \\ ${ }^{1}$ Department of Exceptional Children Psychology, Islamic Azad University, Tehran, Iran \\ ${ }^{2}$ Pediatrics Neurorehabilitation Center, University of Social Welfare and Rehabilitation Sciences, Tehran, Iran \\ ${ }^{3}$ Department of Orthosis and Prosthesis, University of Social Welfare and Rehabilitation Sciences, Tehran, Iran
}

Email address:

Dockm1358@yahoo.com (K. Moghaddam)

${ }^{*}$ Corresponding author

\section{To cite this article:}

Kaveh Moghaddam, Aida Ravarian, Farhoud Saied Ershadi. Painting Therapy in Improvement of the Symptoms of Children with Autism Spectrum Disorder. Psychology and Behavioral Sciences. Vol. 8, No. 3, 2019, pp. 79-84. doi: 10.11648/j.pbs.20190803.14

Received: December 27, 2018; Accepted: April 1, 2019; Published: July 8, 2019

\begin{abstract}
Objective: Children with autism spectrum disorder suffer from problems such as qualitative impairment in the social interactions and stereotypical behaviors and the purpose of many interventions is the dynamic involvement of the families in the treatment and rehabilitation of these children. Therefore, the purpose of this study was to investigate the effect of educational application of family-centered painting techniques on social interactions and stereotypical behaviors of children with autism spectrum disorder. Methods: This applied experimental study was conducted using the pre-test-posttest with follow-up and control group design. In this study, 20children with autism spectrum disorder and their parents were selected by the available sampling method and then, they were randomly divided into experimental and control groups. Then, the Gilliam Autism Rating Scale-I questionnaire was applied at pre-test, posttest and follow-up stages and educational application of family-centered painting techniques was applied just for the experimental group. Then the data were analyzed by the ANCOVA and the repeated measures as statistical methods. Results: An alpha of 0.05 was considered as the significance level and the results showed a significant difference between experimental and control groups in social interactions and stereotypical behaviors of the children. Follow-up tests showed a significant difference and durability, as well. Conclusions: The results showed that educational application of family-centered painting techniques can play an effective and durable role in improvement of social interactions and stereotypical behaviors of the children with autism spectrum disorder.
\end{abstract}

Keywords: Family-centered, Social Interactions, Stereotypical Behaviors, Autism Spectrum Disorder

\section{Introduction}

Painting is a mental association that teenagers, adults and especially children, can interact with others. That is why can understand the child's mood, desires and personality using their paintings and of course, this orientation is effective in their educational guidance, because by painting, children experience discipline in thought and psychomotor skills in the hands $[1,2]$. Child's painting is a message and moves us what he cannot verbalize, and to review and understand the "language" of painting, offers useful information for the parents, educators, psychologists and all those who want to understand and get the mysteries of the child's world. Child experiences all of issues by painting; tests and builds the" ego ". Drawing lines are a reflection of the emotional world, and painting is solely as a world that is transforming parallel to increase in the alertness and transformation of the child [2]). Painting is very important in the formation of character and mind of the child, not only to enable the child to identify environment and company in it as well as raising questions, but also allows child formulates issues that are irregularly raised from all sides. In the drawings, like dreams and visions, child will release ego from the ban and speaks us in the subconscious state of the issues, discoveries and apprehensions. Therefore, it must be said that children painting is not merely fostering creativity and sophistication of the child and or an index of evolution, and it should be considered as a medium of research and exchange with the social environment - with the world of adults who are around 
the child- and as a sign of the child's emotional states [3, 47]. In addition, the painting is considered as a means to measure intelligence, spatial perception and the projection of feelings, emotions and personality of the child; furthermore, all studies in the field of paintings of children show the importance of this art's role in the cohesion and the formation of the child's character; in addition, painting adjusts and improves their information exchange and communication with the environment, and also highly help children for intellectual development and learning, and in general all people use paintings to convey their thoughts and fantasies or feelings and perceptions to others. [8, 9-12]. There is another important point that visual painting as an art in which the aesthetic element is completely evident, can cause discharge and release children's feelings, emotions and sentiments by affecting the limbic system of the brain; furthermore, based on other studies in the art neuropsychology field, elements such as colors, shapes, sizes and penumbra that are seen in painting, are interpreted and processed as visual data and information in the occipital lobe of the right hemisphere, where is place of interpretation, processing and finally the perception of visual data; then, by the activation of the brain lobe it causes improvement of the visual perception skills such as eye-hand coordination, understanding spatial relationships, visual memory, understanding the shape stability and visual accuracy in children, and therefore increases their learning and perception [13, 14-17].

In the paintings of children with autism spectrum disorder or ASD, who suffer difficulties in social interaction, verbal communication, and stereotypical behaviors, when human image is displayed, always is small in size, and details of the face and extremities are rarely shown. For example, if dummies drawn by a child, have the eye, the eye is thoughtful with a look at remote or completely devoid of a look. If the child has high performance and or wholly he or she can paint, while drawing several dummy, he or she paints all of them uniformly and the same. Sometimes also, aggression is seen in their paintings $[18,19]$. Usually due to touch defensive in the limbs, especially hands and fingers, children with autism spectrum disorders cannot look colored pencils, pens, crayons and other drawing and painting in the hands for a long time that is why parents and teachers are complaining of poor handwriting, lack of attention to drawing and lack of focus on writing and drawing for a long time. Hence, most of these children do not have much interest in drawing and painting and their paintings are frequently uniform and in some cases, appear garbled and scrawl and it seems that they have been fixed in the early stages of the evolution of painting, i.e. scrawl. Free painting it is a stereotype among them, and always they paint only a picture [20]. These children, unlike the normal children, cannot reflect their feelings, emotions, fears, happiness and generally, emotions in their paintings. For example, normal children can describe the events that had happened to them, and can project their feelings and emotions towards a friend, parent, or peers in his paintings. While children with the autism spectrum disorder, such as children with mental retardation, due to the lack of sufficient attention and focus, and relatively low learning and IQ, are not able to portray the issues surrounding themselves and fail projection in their paintings and feel powerless for drawing what is in their immediate environment. A variety of colors and shape in most of their paintings are low, and symbols, objects, and images in their paintings are stereotypical and uniform [21]. Furthermore, art therapy studies show that these children pay more attention to sensory stimuli, such as color and shape that are the main elements, rather than human stimuli, in the painting; moreover, clinical studies and research in the field of education of painting and art therapy among the children show that by painting we can reduce somewhat the stereotypical behaviors and movements in this group of children and improve interpersonal communication among them; in fact, in some ways these children, however with a limited manner, express their thoughts and feelings through painting [22-29].

In fact, fundamental problems in drawing and painting of children with autism spectrum disorder that create particular problems in the educational environment for them and along their main symptoms, i.e. the deficiency in interpersonal communication, poor verbal skills, and stereotypical behaviors cause the family, especially the parents of the children face many challenges and the various aspects of life are overshadowed [30, 31]. To alleviate such specific problems that there are in families of the children, extensive studies have been conducted. The purpose of many of these studies has been applying the so-called family-centered interventions and approaches that by using them and by involving the parent in these programs actively and dynamically, we can reduce not only problems of these children, but also create greater interaction between family members, especially their parents in order to more satisfaction with life in the existing conditions for them and preserve the mental health of the family [31-34]. However, this study sought to address this issue that educational application of family-centered painting techniques to what extent can improve the symptoms of autism spectrum disorder, i.e. stereotypical behaviors and social interactions among the children with autism spectrum disorder and whether the impact of this program on these symptoms can be durable?

\section{Methodology}

\subsection{Participants and Methods}

In this applied and experimental research, a pre-test- posttest and control group, and follow-up design has been used for conducting it. The study population included all children with autism spectrum disorder, along with their parents, who were refered to the rehabilitation centers and exceptional schools in Tehran in order to receive the educational and rehabilitation services. The sample consisted of 6-11-year-old children with autism spectrum disorder $(\mathrm{N}=20)$ along with their parents. The subjects were selected from among the 
children in the school for children with autism spectrum disorder by a convenience sampling method. Importantly diagnosis of autism spectrum disorder for these children was done by special education and training organization and using the ADI-R test. After random selection, the subjects were divided into two groups: experimental and control; then, all 20 children with autism spectrum disorder and their parents were taken pre-test and then, for 10 children in the experimental group together with their parents, the familycentered painting techniques program was conducted in 15 sessions of 45 minutes to an hour in the center. Simultaneously, the parents conducted 15 training sessions in touch with their children at home. After finishing 30 sessions, all groups of children and their parents were taken the post - test. And after post-test, follow-up program also was done in a three month and after completion of a threemonth follow-up period, children and parents of two groups were follow-up.

\subsection{Materials and Measures}

In this study, to assess symptoms of autism spectrum disorder or ASD, the GARS- I questionnaire was used. In a study to validate the Gilliam Autism Rating Scale (GARS) by Ahmadi et al. (2011) on children and adolescents with ASD in the Isfahan, the study population consisted of all children and adolescents with ASD Isfahan province, of these 100 subjects were selected by simple random sampling (12). In this study, descriptive and analytical methods were used and data were collected using GARS and the Childhood Autism Rating Scale (CARS). The face validity and content validity of these scales were confirmed by the Esfahan Autism Center's experts. To estimate the construct validity, the CARS was used simultaneously that the correlation coefficient of these two questionnaires was 0.80 . The reliability of this scale using Cronbach's alpha coefficient was 0.89 . Results showed that the GARS is a reliable tool for diagnosing and screening ASDs. Furthermore, the results obtained from this study are consistent with previous research and according to good reliability and validity of this scale, it can be used in research and clinical settings. The results also showed that there is no a significant correlation between age and overall score of autism, and only stereotypes have a significant relationship with age. The results also showed that the GARS test is not gender- sensitive [24].

\subsection{Procedure}

In educational application of family-centered painting techniques, which is derived from studies and clinical trials conducted by Case \& Dalley (2008), Silvers (2008), Zadehmohamdi and Rajabi (2011), Landgartn (2003), Martin (2009) and kamkar Yazdannezhad (2006), a combination of a variety of painting ways such as free painting, painting based on the evolution of painting, copying the shapes of the patterns and images, coloring pictures and shapes, painting of family, drawing of the homunculus and painting with contrasting colors (green, red, yellow and purple, blue and orange, black and white, red and black, pink and gray) were used; and tools of painting and drawing also were diverse and included colored pencils, crayons, gouache and finger paint. Furthermore, in this application, the main symptoms of children with autism spectrum disorders, namely the existence of stereotypical behaviors and the qualitative defects in social interactions as the two sets of main symptoms consistent with the DSM V (2013) have been considered. In the training sessions with the children, this application was instructed to parents, so that they observe them and then, they run and follow it themselves for children at home. To analyze research data, descriptive indicators such as mean and standard deviation were used, and also, according to the number of dependent variables and followup courses, analysis of covariance (ANCOVA) and the repeated measures tests with the help of SPSS software were used. An ANCOVA was used because for determining normality of scores, if the number of participants is 40 or less, Kolmogorov-Smirnov and Shapiro-Wilk tests are used. Otherwise, report of values of a distribution index: tilt and strain or visual depiction of score chart will suffice. Because the sample size of the study groups is less than 40 people and based on the results of the Shapiro-Wilk test, because the values obtained from these tests in a group at a 0.05 level is not significant, so, the condition of equality of intragroup variances and normality distribution of data is met.

\section{Results}

First hypothesis: educational application of familycentered painting techniques is effective in the social interactions of children with ASD.

Table 1. A summary of the results of ANCOA of the first hypothesis.

\begin{tabular}{|c|c|c|c|c|c|c|c|}
\hline $\begin{array}{l}\text { Indicator } \\
\text { Sources of changes }\end{array}$ & Sum of squares & DF & MS & $\mathbf{F}$ & Significance level & Coefficients for ETA & Power of Test \\
\hline Effect of pre-test & 1014.959 & 1 & 1014.959 & 185.437 & 0.000 & 0.925 & 1.000 \\
\hline Effect of group & 76.135 & 1 & 76.135 & 13.910 & 0.002 & 0.481 & 0.936 \\
\hline Error & 82.100 & 15 & 5.473 & & & & \\
\hline Total & 1107.000 & 17 & & & & & \\
\hline
\end{tabular}

According to the data in Table 1 , the value of $F=13.910$ with degrees of freedom. (1 and 15) in the studied variable at the level of $\alpha=0.05$ is significant. Therefore, we can conclude that the application has a significant effect on the social interactions of children with ASD. ETA showed that the amount of the effect of the application in the social interactions of these children is $1.48 \%$. So, the research hypothesis is confirmed with $95 \%$ confidence.

The second hypothesis. The effectiveness of familycentered painting application in the social interactions of 
children with ASD remained stable after three months.

Table 2. Results of the four characteristics of the F related to the analysis of the repeated measurements of the test of follow-up - social interactions (experimental group).

\begin{tabular}{lllllll}
\hline \multirow{2}{*}{ Sources of changes } & Indicator & Sum of square & DF & MS & F & Significance level \\
\hline \multirow{3}{*}{ Effect of } & Sphericity assumed & 62.600 & 2 & 31.300 & 12.982 \\
time & Greenhouse-Geisser & 62.600 & 1.310 & 47.773 & 12.982 \\
& Hewitt- Flett & 62.600 & 1.444 & 43.352 & 12.982 & 12.982 \\
& High band & 62.600 & 1.000 & 62.600 & 0.002 \\
\multirow{2}{*}{ Error } & Sphericity assumed & 43.400 & 18 & 2.411 & 0.002 \\
& Greenhouse-Geisser & 43.400 & 11.793 & 3.680 & \\
& Hewitt- Flett & 43.400 & 12.996 & 3.340 & \\
\hline
\end{tabular}

As it can be concluded from the above table, the statistical characteristic of $F$ with a value of 12.982 of the time factor at a significance level of $\alpha=0.05$ is significant, i.e. it can be concluded that the change (increase) at the various stages of the test is significant. Also in table 3, results of different stages of Bonferroni post-hoc test in the test group showed that the means of the three stages of the pre-test, post-test and follow-up are significantly different. So, the effectiveness of the application in these children's social interactions after three months has remained stable.

Table 3. Results of Bonferroni follow-up test of the results of analysis of repeated measurements in the test of follow-up-social interactions.

\begin{tabular}{lllll}
\hline J-I & & Mean difference (I - J) & SD & Significance level \\
\hline \multirow{2}{*}{ Pre-test } & Post-test & $2.200^{*}$ & 0.512 & 0.006 \\
& Follow-up & $3.500^{*}$ & 0.910 & 0.012 \\
Post-test & Pre-test & $-2.200^{*}$ & 0.512 & 0.006 \\
& Follow-up & 1.300 & 0.597 & 0.172 \\
Follow-up & Pre-test & $-3.500^{*}$ & 0.910 & 0.012 \\
\end{tabular}

The third hypothesis. The educational application of family-centered painting is effective in the stereotypical behaviors of children with ASD.

Table 4. Summary of results of ANCOA of the third hypothesis.

\begin{tabular}{|c|c|c|c|c|c|c|c|}
\hline $\begin{array}{c}\text { Indicator } \\
\text { Sources of changes }\end{array}$ & Sum of squares & DF & MS & $\mathbf{F}$ & Significance level & Coefficients of ETA & Power of test \\
\hline Effect of pre-test & 643.382 & 1 & 643.382 & 84.286 & 0.000 & 0.849 & 1.000 \\
\hline Effect of group & 50.441 & 1 & 50.441 & 6.608 & 0.021 & 0.306 & 0.671 \\
\hline Error & 114.500 & 15 & 7.633 & & & & \\
\hline Total & 765.000 & 17 & & & & & \\
\hline
\end{tabular}

According to the data in Table 4, the value of $F=$ degrees of freedom ( 1 and 15) in the variables studied at a level of $\alpha=0$. 05 is significant. Therefore, it can be concluded that the application has a significant effect on the stereotypical behavior of children with ASD. And the value of the ETA indicates that the effect of the educational application of family-centered painting on the stereotypical behavior of these children is $30.6 \%$. So, the research hypothesis is confirmed at $95 \%$ level of confidence.

The fourth hypothesis. The effectiveness of the educational application of family-centered painting in the stereotypical behavior of children with ASD after three months remains stable.

Table 5. Results of the four characteristics of the F related to the analysis of repeated measurements related to the test of follow-up - stereotypical behaviors (experimental group).

\begin{tabular}{|c|c|c|c|c|c|c|}
\hline \multicolumn{2}{|c|}{ Sources of changes } & Sum of squares & DF & MS & $\mathbf{F}$ & Significance level \\
\hline \multirow{4}{*}{$\begin{array}{l}\text { Effect of } \\
\text { time }\end{array}$} & Sphericity assumed & 88.867 & 2 & 44.433 & 31.822 & 0.000 \\
\hline & Greenhouse-Geisser & 88.867 & 1.743 & 50.976 & 31.822 & 0.000 \\
\hline & Hewitt- Flett & 88.867 & 2.000 & 44.433 & 31.822 & 0.000 \\
\hline & High band & 88.867 & 1.000 & 88.867 & 31.822 & 0.000 \\
\hline \multirow{3}{*}{ Error } & Sphericity assumed & 25.133 & 18 & 1.396 & & \\
\hline & Greenhouse- Geisser & 25.133 & 15.690 & 1.602 & & \\
\hline & High band & 25.133 & 9.000 & 2.793 & & \\
\hline
\end{tabular}

As It can be concluded from the above table, the statistical characteristic of F with a value of 31.822 of the time factor at a 
significance level of $\alpha=0.05$ is significant, i.e. with $95 \%$ probability, it can be concluded that the change (increase) at the various stages of the test is significant. Also in table 6, results of Bonferroni post-hoc test in different stages in the test group showed that the means of the three stages of the pre-test, post-test and follow-up are significantly different. So, the effectiveness of the application in the stereotypical behavior of these children after three months has remained stable.

Table 6. Results of Bonferroni follow-up test of the results of analysis of repeated measurements in the follow-up-stereotypical behaviors test.

\begin{tabular}{lllll}
\hline J-I & & Mean difference (I - J) & SD & Significance level \\
\hline \multirow{2}{*}{ Pre-test } & Post-test & $4.100^{*}$ & 0.526 & 0.000 \\
& Follow-up & $2.900^{*}$ & 0.433 & 0.000 \\
Post-test & Pre-test & $-4.100^{*}$ & 0.526 & 0.000 \\
& Follow-up & -1.200 & 0.611 & 0.243 \\
Follow-up & Pre-test & $-2.900^{*}$ & 0.433 & 0.000 \\
& Post-test & 1.200 & 0.611 & 0.243 \\
\hline
\end{tabular}

\section{Discussion}

According to the data analysis and findings obtained from the present study, the effect of the educational application of family-centered painting on improvement of the symptoms of children with autism spectrum disorder or ASD can be associated with primarily to the durability of the art's effects in the brain and the cerebral hemispheres. Because repeat of this application's exercise can strengthen neuropsychologically performance of perceptual, linguistic, cognitive, emotional and motor parts of the brain and activate it. Secondly, these exercises helped the children with autism spectrum disorder using painting, as long as due to speech and language problems they cannot entirely use the word in order to express their feelings and purposes, fill this vacuum and transfer their feelings and emotions to the opposite side in order to take a step towards the desired social interaction.

\section{Conclusion}

However, the start of teaching drawing to these children empowers their cerebral hemispheres and accelerates the transformation of painting among the children. These findings are consistent with the findings of Landgartn (2003), Silvers (2008), Case \& Dalley (2008), Zaidel (2006), Rajabi and Zadehmohammadi (2011) and the American Association of Art Therapy (2009). Furthermore, features of being stereotyped, repetitive and pointless in paintings are completely evident and in fact, one of the main symptoms of ASD is the same as being stereotyped behaviors and movements. In fact, one of the main symptoms of autism spectrum disorders so stereotyped behavior and movements. But to use practices of the application of family-centered paintings, particularly free painting, education of painting based on the stages of its development, copies of the pictures, coloring images and painting with contrasting colors in terms of diversity, and its attractive and flexible and beautiful structure, and by attracting child's attention, can make a gradual change in their routine and stereotyped behaviors and movements, especially the movements of hands and fingers. In fact, one-dimensional, restricted and stereotyped look of these children limits them in isolation and stereotypes with a higher rate, and does not allow them to communicate with the environment. But change and diversity in practices of the application, especially the practices such as painting with contrasting colors and step by step drawing of the homunculus helped the children to create a flexible and gradual change in their movement, and compromise the changes made. These findings are consistent with the findings of Landgartn (2003), Silvers (2008), Case \& Dalley (2006), Kamkar Yazdannezhad (2006) and American Association of Art Therapy (2009) is consistent coordination. In this study, paintings of educational application of familycentered painting was run in such a way that the main symptoms of ASD. i.e. stereotypical behaviors and social interactions will be affected. The results and findings of this study showed that the presence of a sense of flexibility and aesthetics of art can create diversity and fundamental changes and more relation with the environment of the children.

Children with ASD with sensory stimuli such as color and shape establish better relationships and to combine these stimuli with human drivers because parents can fill and improve the communicative, social, behavioral and affective gaps in them. In addition, the active participation of parents as the two important members of the family in the research indicated that tools of an art such as painting, can have a constructive effect in the relationship between the children and their family members (parents in the study) facilitate their social and communication skills with their parents, increase sense of psychological security and comfort in them and change and target their stereotypes.

However, some of the fathers of the children somewhat had working poor in this study, and the most cooperation was done by mothers, but, as a final point, it is suggested that the application of the family-centered painting, alongside other therapeutic and educational approaches and interventions of children with ASD, be instructed to parents of these children and be run as a palliative - supportive approach in environment such as homes, special schools, and rehabilitation clinics in conjunction with these children.

\section{Acknowledgements}

The authors would like to acknowledge the assistance of staff in Aieen Mehrvarzi School (School for children with autism spectrum disorder), Tehran, Iran. 


\section{References}

[1] Kamkar Yazdannezhad L. The ratio of Arts and mental health improvement of children. Tehran: Faculty of Art and Architecture; Islamic Azad University; Central Tehran Branch; 2006.

[2] Dadsetan. P. Evaluation of children's character based graphical tests. 6th ed .Tehran: Roshd Publications; 2011.

[3] Oliverio Ferraris A. Children's painting and its concepts. 10th ed. Tehran: Dastan publications; 1996.

[4] J. S. Motivational painting and its application in assessing emotional and cognitive skills. Tehran: Roshd Publication; 2001.

[5] Thomas JaS, A. M. J. An Introduction to the Psychology of Children's Drawings. 5th ed. New York: Harvester Wheatsheaf; 1990.

[6] A Z. Neuropsychology \& Art. USA: Psychology press; 2006.

[7] Case CD, T. Art Therapy with children from Infancy to Adolescence. Newyork \& London: Routledge; 2008.

[8] Ozonoff S, Heuny K, Byrd R, Hansen R and Hertz-Picciotto. The Onset of Autism: Patterns of Symptom Emergence in the First Years of Life. 2008: 320-28/ DOI:10.1002/aur.53.

[9] Association AAT. About Art Therapy, 2009.

[10] Case C, Dalley, T. Working with children in Art Therapy. 2nd ed. London: Rutledge; 2006.

[11] Case C, Dalley, T. The Handbook of Art Therapy. 2nd ed. London: Routledge; 2006.

[12] J. S. Art therapy for Autistic Children and adolescents. Tehran: Fararavan; 2008.

[13] Landgartn HB. The Art of clinical treatment. 2nd ed. Tehran: DanzhehPublication; 2003.

[14] Martin N. Art Therapy \& Autism: overview \& Recommendations. journal of the American Art Therapy Association. 2009; 26 (4): 90-187.

[15] Rajabi Behjat b. Design and testing an art therapy program to improve social interaction of $6-12$ - year autistic students. Tehran: Al-Zahra University; 2011.

[16] . Soichiro M, Yasuyo M, Junichi Y. Gaze Behavior of Children with ASD toward Pictures of Facial Expression. Autism Res Treat. 2015; 2015: 617190. Published online 2015 May 19. doi: $10.1155 / 2015 / 617190$.

[17] Patten E,. Ausderau K K,. Watson L R,. Baranek G T. Sensory Response Patterns in Nonverbal Children with ASD. Autism Res Treat. 2013; 2013: 436286. Published online 2013 July 15. doi: $10.1155 / 2013 / 436286$.

[18] Ganji M. Psychopathology according to DSM V. 3rd ed. Tehran: Publication of Savalan; 2013.

[19] Pooheidar M. Comparison of individual and group training effect on mental health and stress in parents of children with autism spectrum disorders. Tehran: Islamic Azad University of Tehran; 2011.
[20] Anderson B. M, Schnetz- Boutaud N, Bartlett J, Wright H. H, Abramson R. K, Cuccaro M. L, Gilbert JR, Pericak-vance M. A and Haines J. L. Common Genetic Variation in Genes related to dopamine. 2008: 364-69/DOI: 10.1002/aur.55.

[21] Chitgarzadeh P. The mental health of mothers of children with autism. Tehran: Iran University of Medical Sciences and Health Services; 2010.

[22] Wall K. Education and care of adolescents and adults with autism- guide for parents and professionals. Tehran: DanzhehPublication; 2004.

[23] Wall K. Autism \& Early years practice. London: paul, chapman; 2006.

[24] Ahmadi SJS, T; Hemmatian, M; Khalili, Z.. Evaluation of psychometric indicators OF diagnostic test for autism (Gars). Journal of Cognitive and Behavioral Sciences' Studies. 2011; 1: 87-104.

[25] Ruzich, E. Allison C, Smith P, Auyeuny H. R, Baron-Cohen, S. The Autism-Spectrum Quotient in Siblings of People with Autism.. 2016, 10 (2): 289-97 / DOI: 10.1002/aur.1651.

[26] Botle S, Poustka, F and Constantino J. N. Assessing Autistic Traits: Cross-cultural Validation of the Social Responsiveness Scale (SRS): 2008.: 354-63 / DOI: 10.1002/aur. 49.

[27] Gidley Larson J. C, Mostofsky S. Evidence That the Pattern of Visuomotor Sequence Learning is altered in Children with Autism. 2008: 341-53/ DOI: 10.1002/aur.54.

[28] Kose S et al. Broader Autistic phenotype in Parents of Children with Autism: Autism Spectrum Quotient -Turkish Version. Psychiatry Clinical Neuroscience, 2013, 67 (1), 20-27.

[29] Greet L, Jarymke M, Hannah B, Lotte van E, Karla Van L, Ilse N. Parenting Behavior in Mothers of Preschool Children with ASD: Development of a Self-Report Questionnaire. Autism Res Treat. 2015; 2015: 381236. Published online 2015 October 29. doi: $10.1155 / 2015 / 381236$.

[30] Douglas D. Potter, S W. Normal Gaze Cueing in Children with Autism Is Disrupted by Simultaneous Speech Utterances in "Live" Face-to-Face Interactions. Autism Res Treat. 2011; 2011: 545964. Published online 2011 November 24. doi: $10.1155 / 2011 / 545964$.

[31] Rezendes D L, Scarpa A. Associations between Parental Anxiety/Depression and Child Behavior Problems Related to Autism Spectrum Disorders: The Roles of Parenting Stress and Parenting Self-Efficacy. Autism Res Treat. 2011; 2011: 395190. Published online 2011 December 13. doi: 10.1155/2011/395190.

[32] Skoyles J R. Autism, Context/Noncontext Information Processing, and Atypical Development. Autism Res Treat. 2011; 2011: 681627. Published online 2011 August 14. doi: $10.1155 / 2011 / 681627$.

[33] Samadi S A, McConkey R. Autism in Developing Countries: Lessons from Iran. Autism Res Treat. 2011; 2011: 145359. Published online 2011 December 25. doi: 10.1155/2011/145359.

[34] Waters P, Healy O. Investigating the Relationship between SelfInjurious Behavior, Social Deficits, and Cooccurring Behaviors in Children and Adolescents with Autism Spectrum Disorder. Autism Res Treat. 2012; 2012: 156481. Published online 2012 November 7. doi: 10.1155/2012/156481. 